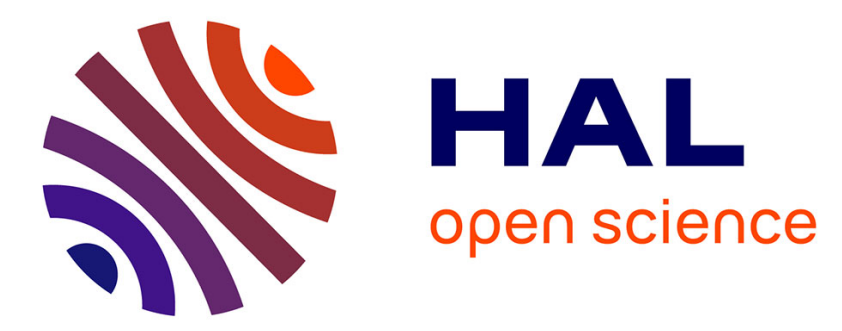

\title{
Preferential CO oxidation in hydrogen-rich stream over an electrochemically promoted $\mathrm{Pt}$ catalyst
}

A. de Lucas-Consuegro, A. Princivalle, A. Caravaca, A. Dorado, C. Guizard, J. L. Valverde, P. Vernoux

\section{- To cite this version:}

A. de Lucas-Consuegro, A. Princivalle, A. Caravaca, A. Dorado, C. Guizard, et al.. Preferential CO oxidation in hydrogen-rich stream over an electrochemically promoted Pt catalyst. Applied Catalysis B: Environmental, 2010, 93 (3-4), pp.281-287. 10.1016/j.apcatb.2009.11.019 . hal-00639069

\section{HAL Id: hal-00639069 https://hal.science/hal-00639069}

Submitted on 4 Oct 2021

HAL is a multi-disciplinary open access archive for the deposit and dissemination of scientific research documents, whether they are published or not. The documents may come from teaching and research institutions in France or abroad, or from public or private research centers.
L'archive ouverte pluridisciplinaire HAL, est destinée au dépôt et à la diffusion de documents scientifiques de niveau recherche, publiés ou non, émanant des établissements d'enseignement et de recherche français ou étrangers, des laboratoires publics ou privés.

\section{(c)(1)}

Distributed under a Creative Commons Attribution| 4.0 International License 


\title{
Preferential CO oxidation in hydrogen-rich stream over an electrochemically promoted Pt catalyst
}

\author{
A. de Lucas-Consuegra ${ }^{\mathrm{a}, \mathrm{b}, *}$, A. Princivalle ${ }^{\mathrm{b}}$, A. Caravaca ${ }^{\mathrm{a}}$, F. Dorado ${ }^{\mathrm{a}}$, C. Guizard ${ }^{\mathrm{b}}$, \\ J.L. Valverde ${ }^{a}$, P. Vernoux ${ }^{b}$ \\ a Departamento de Ingeniería Química, Facultad de Ciencias Químicas, Universidad de Castilla-La Mancha, Avenida Camilo Jose' Cela 12, 13005 Ciudad Real, Spain

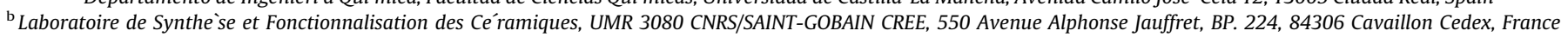

\begin{abstract}
We have conducted a study on the preferential CO oxidation in hydrogen-rich stream (PROX) coupling catalysis and electrochemistry, i.e., by using an electrochemical catalyst $\left(\mathrm{Pt} / \mathrm{K}-\mathrm{\beta Al}_{2} \mathrm{O}_{3}\right)$. It was shown that PROX activity and selectivity of a Pt catalyst can be strongly enhanced by electrochemical pumping of potassium ions from the solid electrolyte support. The observed promotional effect was attributed to a decrease in the $\mathrm{CO}$ and $\mathrm{H}_{2}$ chemisorption and to an increase in the $\mathrm{O}_{2}$ chemisorption which led to a relative increase in the $\mathrm{CO}$ oxidation reaction vs. the $\mathrm{H}_{2}$ oxidation. The electrochemical promotion allowed decreasing the operating temperature window of the Pt catalyst and attenuating the inhibiting effect of $\mathrm{H}_{2}$ on both catalytic activity and selectivity. In addition some of the catalytic results were supported by in situ electrochemical characterization techniques such as cyclic voltammetry and open circuit potential measurements. Finally a very interesting permanent NEMCA effect was shown. It demonstrated the high stability of the formed promoting species and the potential for a further development of NEMCA effect in PROX real configurations.
\end{abstract}

\section{Introduction}

The polymer electrolyte membrane fuel cell (PEMFC) has come to be regarded as one of the most promising candidates for utilizing hydrogen to produce heat and electricity, especially for electric vehicles, residential co-generation systems and portable power supplies for small devices [1]. Especially when the PEMFC feed stream is produced by reforming of methanol and hydrocarbons, the gas always contains some amount of $\mathrm{CO}$ as an impurity, which is a poison for the fuel cell anode catalyst. Therefore, the hydrogen production process must be equipped with a $\mathrm{CO}$ removal system. Several methods for the $\mathrm{CO}$ removal have been studied and recently revised by Park et al. [2]: selective $\mathrm{H}_{2}$-diffusion through membranes, $\mathrm{CO}$ methanation and selective $\mathrm{CO}$ oxidation, also known as preferential CO oxidation (PROX) reaction. Among these methods, the PROX process has been considered as the most promising and cost effective one. It consists of the addition of oxygen to a fuel processor effluent in order to preferentially oxidize $\mathrm{CO}$ rather than $\mathrm{H}_{2}$ [3]. Different catalyst systems have been

\footnotetext{
* Corresponding author at: Departamento de Ingeniería Química, Facultad de Ciencias Químicas, Universidad de Castilla-La Mancha, Avenida Camilo José Cela 12, 13005 Ciudad Real, Spain. Tel.: +34 926 95300; fax: +34 926295437.

E-mail address: Antonio.Lconsuegra@uclm.es (A. de Lucas-Consuegra).
}

explored for the PROX reaction [2], including metal oxides, supported gold catalyst and novel metal supported catalysts such as Pt, Ru, Rh and Ir. Platinum supported catalysts are candidates to be used in a fuel processor, due to their ability to operate at high temperatures, their stability for long term operation and their high resistance to deactivation by $\mathrm{CO}_{2}$ or $\mathrm{H}_{2} \mathrm{O}[4,5]$. In real configurations, the PROX unit should be typically placed and therefore operated between the low temperature shift reactor $\left(\approx 200{ }^{\circ} \mathrm{C}\right)$ and the PEMFC $\left(\approx 80^{\circ} \mathrm{C}\right)$. However, the PROX activity of Pt based catalyst is usually limited to temperatures close to $200^{\circ} \mathrm{C}$ [6]. Until now, several efforts have been made to improve this low temperature Pt PROX activity (attributed to the inability of Pt to activate $\mathrm{O}_{2}$ [7]), e.g., using different kinds of supports [8], pretreatment methods [9] and the presence of a second metal [10]. Recent studies [11-16] report that the introduction of alkalis (and especially potassium [16]) is effective for improving the activity and the selectivity of supported noble metal catalyst.

In this work, we propose the use of solid electrolytes as electroactive catalyst supports as a novel approach to improve the catalytic properties of Pt for the PROX reaction through the concept of electrochemical promotion. This phenomenon also known as NEMCA (Non-Faradaic Electrochemical Modification of Catalytic Activity) effect is based on the improvement of the catalytic properties of a heterogeneous catalyst by the electrochemical pumping of promoter ions from the solid electrolyte support 
[17-20]. Until now, this phenomenon has been demonstrated in more than 80 catalytic systems with several important technological possibilities, particularly in industrial product selectivity and in exhaust gas treatment $[21,22]$. However, to our knowledge, there are no previous studies on the direct application of the NEMCA effect for the PROX reaction. Only some recent approaches studying the water gas shift reaction have come from the group of Vayenas [23-25]. In these studies (carried out in a PEMFC configuration [23-25], under $\mathrm{CO}, \mathrm{CO}_{2}, \mathrm{H}_{2}, \mathrm{O}_{2}$ and $\mathrm{H}_{2} \mathrm{O}$ ) the authors found a moderate increase in the $\mathrm{CO}$ removal efficiency using a proton conducting nafion membrane.

Based on the previous mentioned studies about chemical promotion on conventionally dispersed catalyst [11-16], in this work Pt was selected as the catalyst and $\mathrm{K}-\mathrm{\beta Al}_{2} \mathrm{O}_{3}$ as the solid electrolyte. The system was investigated under different reaction temperatures (below $200^{\circ} \mathrm{C}$ ) and under different compositions $\left(\mathrm{H}_{2} / \mathrm{O}_{2}\right.$ ratio). The catalytic experiments were supported by different in situ characterization techniques (open circuit potential measurements and cyclic voltammetry), which provided useful information on the competitive chemisorption of the reactants under different conditions.

\section{Experimental}

\subsection{Preparation of the tubular electrochemical catalyst}

In this study, a tubular reactor design has been used in view of a potential practical application (Fig. 1). It consisted of a tubular K$\mathrm{BAl}_{2} \mathrm{O}_{3}$ tube (supplied by Ionotec) with one end closed (outer diameter $30 \mathrm{~mm}$, thickness $2 \mathrm{~mm}$, length $100 \mathrm{~mm}$ ). The catalystworking electrode (Pt) and the counter electrodes ( $\mathrm{Au}$ ) were symmetrically placed in the outer and inner part of the tube, respectively, by using $\mathrm{Pt}$ and Au pastes (both of them supplied by Metalor) annealed at $800{ }^{\circ} \mathrm{C}$ for $2 \mathrm{~h}$. Both electrodes were placed from the beginning of the end close side of the tube, with a total geometrical Pt catalyst-working electrode area of $35 \mathrm{~cm}^{2}$ and a final Pt metal loading of approximately $1 \mathrm{mg} / \mathrm{cm}^{2}$. The tubular electrochemical catalyst was inserted in a pirex-glass tube of $100 \mathrm{~mm}$ of length and $33 \mathrm{~mm}$ of diameter. The working electrode (W) was exposed to the reactive mixture whereas the counter electrode (C) was under reference air. It should be mentioned that due to the absence of reference electrode in the present configuration we could not measure the Pt working electrode variation. Therefore no direct link between the applied potential $\left(V_{\mathrm{WC}}\right)$ and the Pt catalyst work function could be established on the

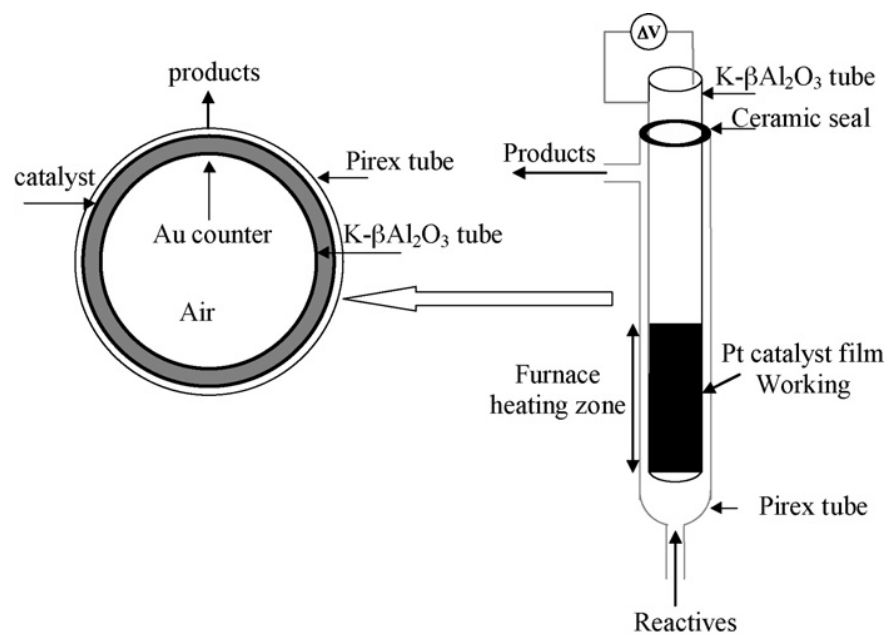

Fig. 1. Schematic drawing of the electrochemical reactor with $\mathrm{Pt} / \mathrm{K}-\mathrm{\beta Al}_{2} \mathrm{O}_{3}$ tube. present configuration. This reactor design allowed having a suitable contact between the reactants and the Pt catalyst-working electrode film. Both electrodes were connected to a potentiostatgalvanostat Voltalab PGZ 402 (Radiometer Analytical).

\subsection{Catalytic activity measurements}

The reaction gases were mixtures of $\mathrm{CO}$ ( $1 \%$ in $\mathrm{He}$ ), $\mathrm{O}_{2}$ ( $1 \%$ in $\mathrm{He}$ ), $\mathrm{H}_{2}$ (40\% in $\mathrm{He}$ ) and pure $\mathrm{He}$, supplied by Air Liquide. The gas composition was controlled by mass flow controllers (Brooks) and it was as follows: $0.4 \% \mathrm{CO}, 0.2 \% \mathrm{O}_{2}$ (which corresponds to the stoichiometric ratio), $0-16 \% \mathrm{H}_{2}$, He balance and an overall flow rate of $15 \mathrm{~L} \mathrm{~h}^{-1}$. Reactant and product gases were analyzed by a microgas chromatograph (Agilent). The micro-chromatograph was composed of two modules, each one equipped with a thermal conductivity micro-detector (TCD). The first module enables the separation of $\mathrm{O}_{2}$ and $\mathrm{CO}$ by using a molecular sieve while the second module allowed separating $\mathrm{CO}_{2}$ and $\mathrm{H}_{2} \mathrm{O}$ by using a poraplot column. The catalytic activity of the system was evaluated on the basis of the following equations:

CO conversion $(\%)=\frac{[\mathrm{CO}]_{\text {in }}-[\mathrm{CO}]_{\text {out }}}{[\mathrm{CO}]_{\text {in }}} \times 100$

$\mathrm{O}_{2}$ conversion $(\%)=\frac{[\mathrm{O}]_{\text {in }}-[\mathrm{O}]_{\text {out }}}{[\mathrm{O}]_{\text {in }}} \times 100$

$\mathrm{CO}_{2}$ selectivity $(\%)=0.5 \times \frac{[\mathrm{CO}]_{\text {in }}-[\mathrm{CO}]_{\text {out }}}{\left[\mathrm{O}_{2}\right]_{\text {in }}-\left[\mathrm{O}_{2}\right]_{\text {out }}} \times 100$

$\mathrm{CO}_{2}$ selectivity was referred to oxygen conversion in order to take into account the simultaneous formation of water by $\mathrm{H}_{2}$ oxidation.

During the catalytic experiments $\mathrm{CO}_{2}$ was the only observed oxidation product and no $\mathrm{CH}_{4}$ was detected under the explored reaction conditions. During the catalytic activity measurements an initial potential of $+2 \mathrm{~V}$ was always applied in order to clean the Pt surface from promoter ions and define a reference state (unpromoted conditions). On the other hand, a decrease in the applied potential or current to negative values implies that potassium ions were electrochemically transferred to the $\mathrm{Pt}$ catalyst film (electro-promoted conditions).

\subsection{In situ characterization measurements}

The possibility of using solid electrolytes as catalyst supports in solid electrolyte cells allows using solid state electrochemistry techniques for in situ monitoring surface activities of the reactant species [18]. Thus, open circuit potential measurements have been carried out under reaction conditions in order to get information about the competitive chemisorption between the reactants.

Cyclic voltammetry was also performed with the potentiostatgalvanostat under different gas compositions and were recorded at a sweep rate of $20 \mathrm{mV} / \mathrm{s}$. Before each cyclic voltammetry an initial potential of $+2 \mathrm{~V}$ was always applied to define a reference state.

\section{Results and discussion}

\subsection{Potentiostatic and galvanostatic transient experiments}

The catalytic behaviour of the tubular Pt/K- $\mathrm{BAl}_{2} \mathrm{O}_{3} / \mathrm{Au}$ electrochemical catalyst for the PROX reaction $\left(\mathrm{CO} / \mathrm{O}_{2} / \mathrm{H}_{2}: 0.4 \% / 0.2 \% / 16 \%\right)$ was firstly investigated by a potentiostatic experiment carried out at $195{ }^{\circ} \mathrm{C}$. Fig. 2 shows the steady state variation of the $\mathrm{CO}$ and $\mathrm{O}_{2}$ conversion as well as the $\mathrm{CO}_{2}$ selectivity under steady state conditions vs. the applied catalyst potential $\left(V_{\mathrm{WC}}\right)$. It can be observed that starting from a positive catalyst potential of $+2 \mathrm{~V}$ 


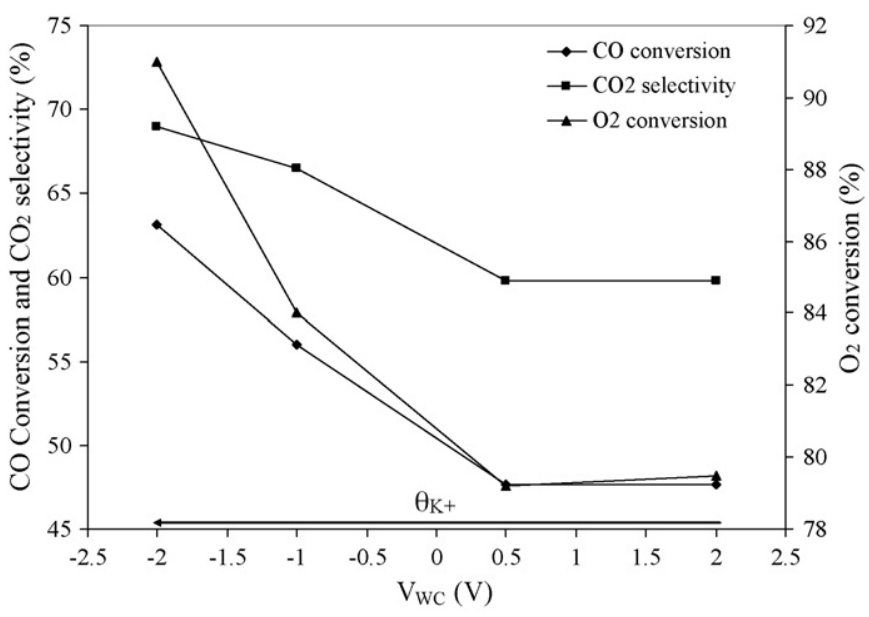

Fig. 2. Steady state effect of applied potential $\left(V_{\mathrm{WC}}\right)$ on the $\mathrm{CO}$ and $\mathrm{O}_{2}$ conversion as well as on the $\mathrm{CO}_{2}$ selectivity. Conditions: $\mathrm{CO} / \mathrm{O}_{2} / \mathrm{H}_{2}: 0.4 \% / 0.2 \% / 16 \%, T=195{ }^{\circ} \mathrm{C}$.

(unpromoted catalyst surface) and then decreasing it, the catalytic performance of Pt strongly improved, increasing the $\mathrm{CO}$ and the $\mathrm{O}_{2}$ conversions as well as the $\mathrm{CO}_{2}$ selectivity. Very interestingly, the $\mathrm{CO}$ conversion and the $\mathrm{CO}_{2}$ selectivity increased from $47 \%$ to $63 \%$ and from $60 \%$ to $69 \%$ when the applied potential decreased from +2 to $-2 \mathrm{~V}$, respectively. According to the current theory of electrochemical promotion, one may rationalize the observed promotional effect on the basis of the electrode work function modification upon applied potential [17-21,26,27]. Thus, a decrease in the catalyst potential and, therefore, in the catalyst work function, led to an increase of the electronic density of Pt, with a concomitant spillover of $\mathrm{K}^{+}$ions from the electrolyte onto the Pt surface [28-31]. According to the recently established chemical and electrochemical promotional rules [27], it led to an improvement of the chemisorption of electron acceptor species at the expense of electron donor ones, modifying the catalytic activity of the system. Thus, the origin of the observed promotional effect, induced by the growing content of electrochemically supplied potassium ions as the applied potential decreased, can be attributed to a relative increase in the $\mathrm{O}_{2}$ coverage (the strongest electron acceptor) at the expense of $\mathrm{CO}$, this latter usually strongly adsorbed on the Pt active sites [30]. This explanation is in good agreement with the previous work of Kuriyama et al. [15] who demonstrated that the chemical addition of potassium on Pt under PROX conditions weakened the interaction between $\mathrm{Pt}$ and $\mathrm{CO}$ modifying the $\mathrm{CO}$ adsorption sites. Additionally, we propose that the presence of electropositive potassium ions decreased the $\mathrm{H}_{2}$ chemisorption since this latter molecule could be considered as an electron donor one (vs. CO and $\mathrm{O}_{2}$ ) [18]. It would explain the relative increase in the $\mathrm{CO}$ oxidation reaction vs. the $\mathrm{H}_{2}$ oxidation one as the applied potential decreased, with the consequent observed enhancement in the $\mathrm{CO}_{2}$ selectivity.

The described potentiostatic experiment is fully consistent with the galvanostatic one shown in Fig. 3. It depicts the response of the $\mathrm{CO}$ conversion and the $\mathrm{CO}_{2}$ selectivity along with the corresponding changes in catalyst potential vs. time under a galvanostatic transient carried out under the same PROX atmosphere $\left(\mathrm{CO} / \mathrm{O}_{2} / \mathrm{H}_{2}\right.$ : $0.4 \% / 0.2 \% / 16 \%, T=195^{\circ} \mathrm{C}$ ). Firstly, the Pt surface was electrochemically cleaned of potassium ions by the application of a positive potential of $+2 \mathrm{~V}$. Then, at $t=10 \mathrm{~min}$ a negative current $I=-20 \mu \mathrm{A}$ was applied for $30 \mathrm{~min}$. Under these conditions, potassium ions were electrochemically transferred from the electrolyte to the $\mathrm{Pt}$ catalyst at a rate equal to $I / F=2.07 \times 10^{-10} \mathrm{~mol} \mathrm{~K} / \mathrm{s}$ according to Faraday's equation. The inserted abscissa indicates the induced

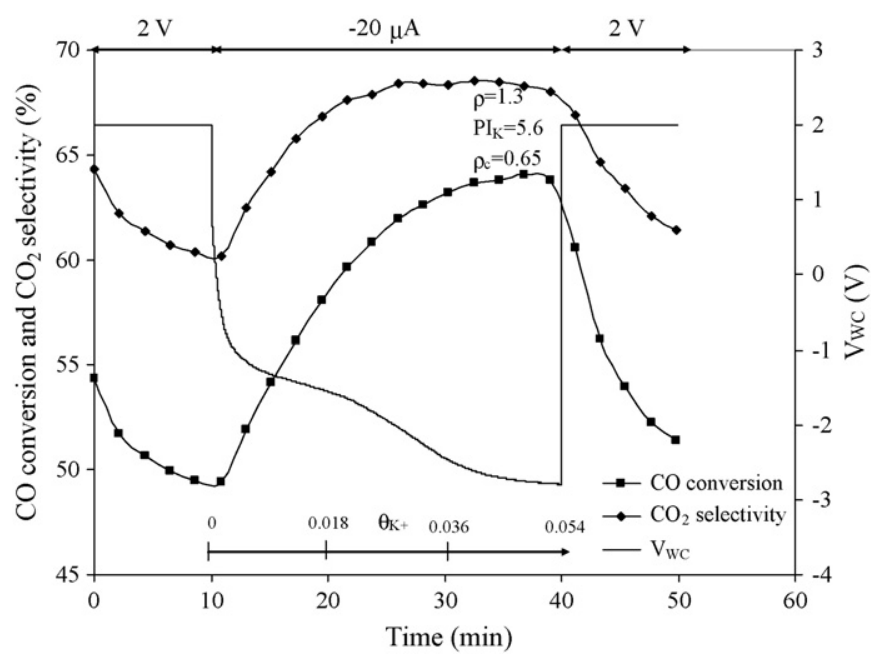

Fig. 3. Transient effect of constant applied current $(I=-20 \mu \mathrm{A})$ on $\mathrm{CO}$ conversion and $\mathrm{CO}_{2}$ selectivity as well as on the catalyst potential $\left(V_{\mathrm{WC}}\right)$. Conditions: $\mathrm{CO} / \mathrm{O}_{2} / \mathrm{H}_{2}$ : $0.4 \% / 0.2 \% / 16 \%, T=195{ }^{\circ} \mathrm{C}$.

change in potassium coverage $\left(\theta_{\mathrm{K}}\right)$ on the Pt surface, calculated using Faraday's law:

$\frac{\mathrm{d} \theta_{\mathrm{K}}}{\mathrm{d} t}=-\frac{I}{F N}$

where $F$ is the Faraday's constant, $N$ is the number of Pt active sites $\left(6.8 \times 10^{-6} \mathrm{~mol}\right)$ obtained following the estimation of previous works [26] and extrapolated for the geometric electrode area, and $t$ is the time of current application in seconds. The maximum polarization effect on the catalytic $\mathrm{CO}$ oxidation reaction rate was characterized by the following promotional parameters [18]: the rate enhancement ratio $(\rho)$, the promotion index $\left(\mathrm{PI}_{\mathrm{K}}\right)$, and the effective rate enhancement ratio $\left(\rho_{\mathrm{c}}\right)$ defined by the Eqs. $(5)-(7)$ :

$\rho=\frac{r}{r_{0}}$

$\mathrm{PI}_{\mathrm{K}}=\frac{\left(\Delta r / r_{0}\right)}{\Delta \theta_{\mathrm{K}}}$

$\rho_{\mathrm{c}}=\frac{\rho}{\rho_{\max }}$

where $r_{0}$ is the catalytic reaction rate under unpromoted conditions $\left(V_{\mathrm{WC}}=+2 \mathrm{~V}\right), r$ is the catalytic reaction rate under promoted ones $\left(V_{\mathrm{Wc}}<2 \mathrm{~V}\right)$ and $\rho_{\max }$ expresses the maximum allowable $\rho$ value due to complete conversion.

It can be observed that under the application of a negative current (electrochemical pumping of $\mathrm{K}^{+}$ions to the Pt surface), the catalytic activity of the system increased by a factor of 1.3 due to the previously discussed strong electronic promotional effect of potassium over the catalyst $\left(\mathrm{PI}_{\mathrm{K}}=5.6\right)$, leading to an effective rate enhancement ratio of 0.65 which shows a good efficiency of the electro-promotional effect. Additionally, it can be observed that after $25 \mathrm{~min}$ of current application, which corresponds to potassium coverage of approximately $\theta_{\mathrm{K}} \sim 0.04$, the catalytic activity of the system almost achieved a steady state value of activity and selectivity. On the other hand in other previous works of chemical promotion of potassium on dispersed $\mathrm{Pt} / \mathrm{Al}_{2} \mathrm{O}_{3}$ catalyst [16] a different optimum potassium amount was found depending on the reaction temperature. It implies that by conventional (chemical) promotion one can hardly prepare an optimum promoted catalyst for the overall temperature range of the PROX reaction $\left(80-200{ }^{\circ} \mathrm{C}\right)$. However, the use of an electrochemical catalyst allows an in situ control of the optimum promoter amount 
depending on the operating conditions [31]. This non-stationary behaviour could be expected on a PROX reactor unit, e.g., between the cold start conditions or after long time working periods. Finally, it can be observed that after a further application of a catalyst potential of $V_{\mathrm{WC}}=+2 \mathrm{~V}$ at $t=40 \mathrm{~min}$, the promoting ions return again to the solid electrolyte, achieving the initial unpromoted conditions, therefore leading to a reversible NEMCA effect.

\subsection{Influence of the reaction temperature}

The influence of the reaction temperature on the PROX activity was firstly investigated under unpromoted conditions, i.e., over a clean Pt surface. Fig. 4 shows the influence of the reaction temperature on $\mathrm{CO}$ and $\mathrm{O}_{2}$ conversion as well as on $\mathrm{CO}_{2}$ selectivity under the following conditions: $\mathrm{CO} / \mathrm{O}_{2} / \mathrm{H}_{2}$ : $0.4 \% / 0.2 \% / 16 \%$, $V_{\mathrm{WC}}=+2 \mathrm{~V}$. As expected, $\mathrm{CO}$ and the $\mathrm{O}_{2}$ conversions increased with the reaction temperature. This behaviour, typically observed on $\mathrm{Pt}$ based catalysts below $200{ }^{\circ} \mathrm{C}[7,9,16]$, is due to an increase in the kinetics of both $\mathrm{CO}$ and $\mathrm{H}_{2}$ oxidation reactions. On the other hand, it can be observed that the $\mathrm{CO}_{2}$ selectivity decreased as the reaction temperature increased. This effect, also observed in a previous work with Pt based catalysts [32], can be explained considering the higher activation energy of the $\mathrm{H}_{2}$ oxidation reaction vs. the $\mathrm{CO}$ oxidation one. At low temperature, $\mathrm{CO}$ completely covers the metallic $\mathrm{Pt}$ surface and, as a consequence, the $\mathrm{CO}$ oxidation reaction mainly takes place (high $\mathrm{CO}_{2}$ selectivity values). However, as the temperature rises, $\mathrm{CO}$ desorption from Pt surfaces becomes important and the $\mathrm{Pt}$ active sites are partially recovered by $\mathrm{H}_{2}$ which favours the $\mathrm{H}_{2}$ oxidation, limiting $\mathrm{CO}_{2}$ selectivity. Therefore, the higher the reaction temperature, the lower the $\theta_{\mathrm{CO}} / \theta_{\mathrm{H}_{2}}$ coverage ratio, i.e., lower $\mathrm{CO}_{2}$ selectivity values [32].

The influence of the reaction temperature was also studied under electro-promotional conditions. Fig. 5 shows the variation of the $\mathrm{CO}$ conversion and $\mathrm{CO}_{2}$ selectivity vs. temperature for different applied catalyst potentials $\left(V_{\mathrm{WC}}=+2,+0.5,-1\right.$ and $\left.-2 \mathrm{~V}\right)$ under the same composition $\left(\mathrm{CO} / \mathrm{O}_{2} / \mathrm{H}_{2}: 0.4 \% / 0.2 \% / 16 \%\right)$. The inset figure also shows the different values of the effective rate enhancement ratio $\left(\rho_{\mathrm{c}}\right)$ obtained for a catalyst potential of $-2 \mathrm{~V}$ at different temperatures. As expected it can be observed that both the unpromoted $\left(V_{\mathrm{WC}}=2 \mathrm{~V}\right)$ and electro-promoted $\left(V_{\mathrm{Wc}}<2 \mathrm{~V}\right)$ conversion increase with the reaction temperature while the $\mathrm{CO}_{2}$ selectivity decreased, in good agreement with the previous results under absence of promoter. However the most important point of this figure is that the application of the negative polarizations, e.g., -1 and $-2 \mathrm{~V}$, led to an increase of the CO oxidation rate for the

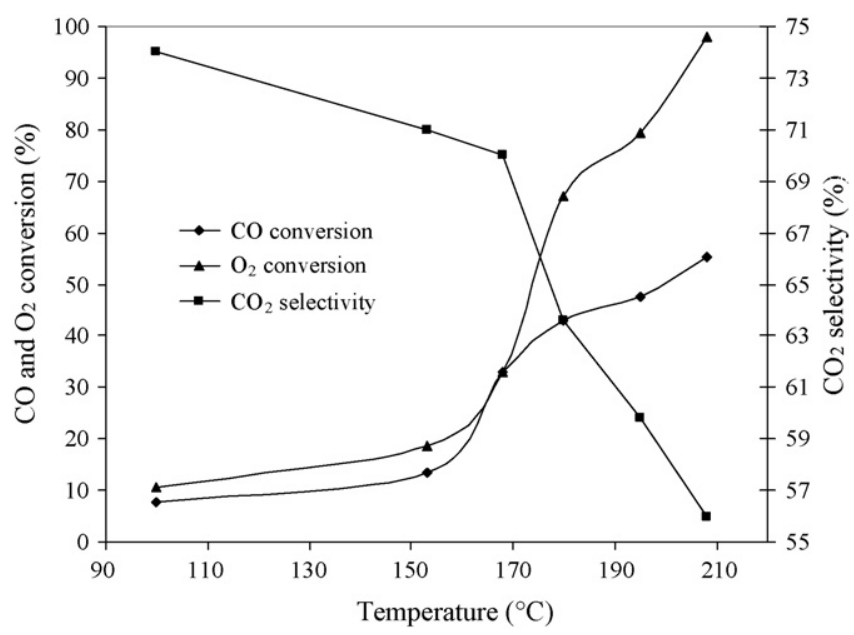

Fig. 4. Influence of the reaction temperature on the unpromoted PROX activity and selectivity, i.e., under application of $2 \mathrm{~V}$. Conditions: $\mathrm{CO} / \mathrm{O}_{2} / \mathrm{H}_{2}: 0.4 \% / 0.2 \% / 16 \%$.
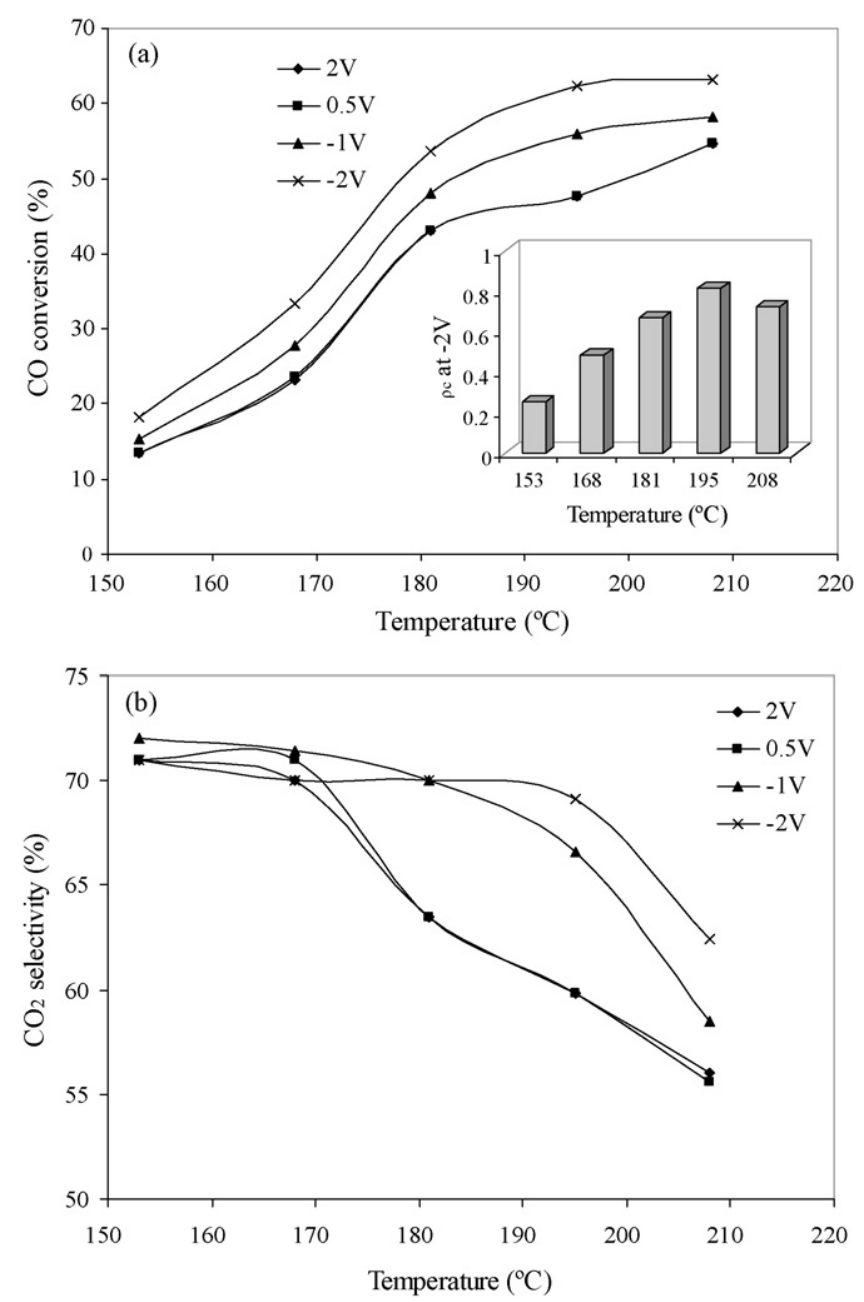

Fig. 5. Influence of the reaction temperature on the $\mathrm{CO}$ conversion (a) and $\mathrm{CO}_{2}$ selectivity (b) at different applied catalyst potential. Inset: variation of the effective rate enhancement ratio $\left(\rho_{\mathrm{c}}\right)$ attained at $-2 \mathrm{~V}$ at different reaction temperatures. Conditions: $\mathrm{CO} / \mathrm{O}_{2} / \mathrm{H}_{2}: 0.4 \% / 0.2 \% / 16 \%$.

whole temperature range. The lower the applied potential was, the higher the observed CO oxidation (higher promoter coverage was electrochemically supplied). Thus, even at very low temperatures $\left(153^{\circ} \mathrm{C}\right)$, the application of a negative polarization led to a slight increase in the activity of the system. It can also be observed that the electro-promotional effect was higher at increasing temperatures, i.e., the effective rate enhancement ratio increased with the reaction temperature. This fact could be attributed to higher promoter coverage on the catalyst surface for a fixed potential as the reaction temperature increases. Then, as the reaction temperature increases both the kinetic of the electrode reaction is faster and the ionic conductivity of the electrolyte is higher. It led to higher rate of ions supply (higher currents were measured during the transients) and consequently to a higher amount of transferred potassium ions. This fact can be confirmed by the increase in the amount of transferred charge. By means of an example, for the applied potential of $-2 \mathrm{~V}$, the total transferred charged increased from $-16 \mathrm{mC}$ at $153^{\circ} \mathrm{C}$ to $-21 \mathrm{mC}$ at $208^{\circ} \mathrm{C}$. Then for fixed potential difference between the working and counter electrode $\left(V_{\mathrm{WC}}\right)$ at higher temperatures higher potassium coverage was supplied increasing the magnitude of the electro-promotional effect.

It is also interesting to note that this observed electropromotional effect led to an activation of the catalyst at lower temperatures. For instance, the $\mathrm{CO}$ oxidation activity under unpromoted conditions at $208{ }^{\circ} \mathrm{C}$ was almost the same as the 
electro-promoted one under application of $-2 \mathrm{~V}$ at $181^{\circ} \mathrm{C}$, thus decreasing $30{ }^{\circ} \mathrm{C}$ the activity window of the system. It shows the interesting possibilities for using the electrochemical promotion to decrease the operating temperature window of a catalyst, with the consequent decrease in the energy requirements [30].

On the other hand, it can be observed that the effect of the applied polarization on the $\mathrm{CO}_{2}$ selectivity depended on the reaction temperature, being the most important promotional effect above $170{ }^{\circ} \mathrm{C}$. At low temperature, the $\mathrm{CO}$ oxidation reaction is already favoured if compared to the $\mathrm{H}_{2}$ oxidation one (high $\mathrm{CO}_{2}$ selectivity values). The increase in the $\mathrm{O}_{2}$ coverage induced by the $\mathrm{K}^{+}$ions enhanced almost in the same level both oxidation reactions ( $\mathrm{CO}$ and $\mathrm{H}_{2}$ oxidation), keeping constant the values of $\mathrm{CO}_{2}$ selectivity. However, as the temperature increased and the $\mathrm{H}_{2}$ coverage began to be relevant (increasing the $\mathrm{H}_{2}$ oxidation reaction), the presence of the promoter ions increased the $\mathrm{CO}_{2}$ selectivity by decreasing $\mathrm{H}_{2}$ adsorption (electron donor molecule). This explanation follows the recent identified rules of chemical and electrochemical promotion [27] and is also in good agreement with previous PROX studies over Pt based catalyst [32].

\subsection{Influence of the $\mathrm{H}_{2} / \mathrm{O}_{2}$ ratio}

Fig. 6 shows the variation of $\mathrm{CO}$ conversion and $\mathrm{CO}_{2}$ selectivity vs. time for the unpromoted $(+2 \mathrm{~V})$ and electro-promoted catalyst $(-2 \mathrm{~V})$ under different $\mathrm{H}_{2} / \mathrm{O}_{2}$ ratios at $195^{\circ} \mathrm{C}$. This figure additionally shows the variation of the open circuit potential $\left(V^{\circ}{ }_{\text {wC }}\right)$ vs. time under different gas compositions. It can be observed that as the $\mathrm{H}_{2}$ composition in the feed increased the

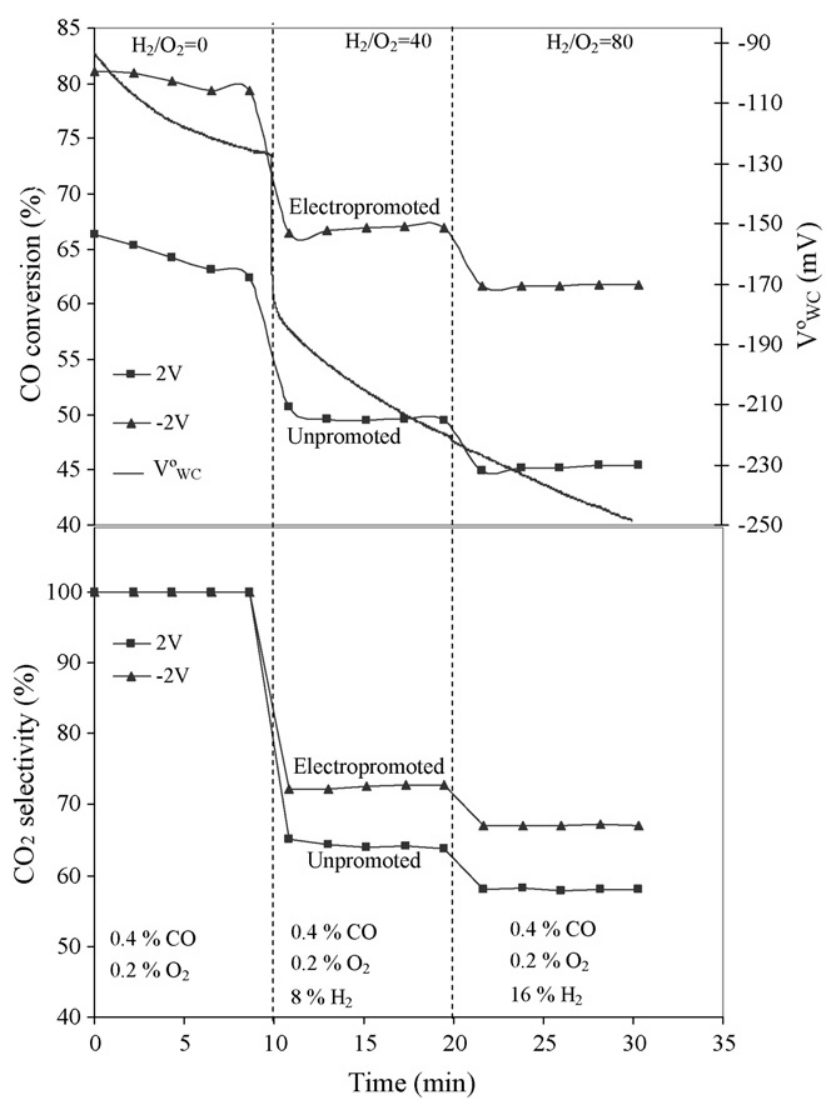

Fig. 6. $\mathrm{CO}$ conversion and $\mathrm{CO}_{2}$ selectivity response vs. time to step changes in the gaseous composition under unpromoted $(2 \mathrm{~V})$ and electro-promoted $(-2 \mathrm{~V})$ conditions. The secondary axis shows the response of the open circuit potential $\left(V^{\circ}\right.$ wc) to step changes in the gaseous composition under open circuit conditions. $T=195^{\circ} \mathrm{C}$. overall catalytic performance of the system decreased for both unpromoted and electro-promoted catalyst. One can suggest that this is an obvious consequence of a progressive increase in the $\mathrm{H}_{2}$ coverage on the catalyst surface which decreases the number of available active sites for the $\mathrm{CO}$ oxidation, favouring the competitive $\mathrm{H}_{2}$ oxidation reaction. However, this behaviour diverges from previous studies carried out with dispersed $\mathrm{Pt} /$ $\mathrm{Al}_{2} \mathrm{O}_{3}$ catalysts which have shown a promotional effect of $\mathrm{H}_{2}$ in the $\mathrm{CO}$ oxidation reaction at temperatures below $150{ }^{\circ} \mathrm{C}[15,16]$. In these earlier studies, the promotional effect of $\mathrm{H}_{2}$ was attributed to the formation of hydrogen-containing oxidizing species such as hydroxyl group $(\mathrm{OH})$, which can promote the $\mathrm{CO}$ oxidation reaction $[33,34]$. In our case, we can envisage that the formation of such promoting hydroxyl group $(\mathrm{OH})$ did not take place, which could be justified attending to the different experimental conditions $\left(\mathrm{H}_{2} / \mathrm{O}_{2}\right.$ ratio and reaction temperature) and/or the different morphology of the catalysts prepared in each study (dispersion and particle size). However, it is clear that the presence of the electrochemical promoter strongly increased the activity and the selectivity of the system, attenuating the inhibiting effect of $\mathrm{H}_{2}$ (Fig. 6). For instance, the application of a catalyst potential of $-2 \mathrm{~V}$ approximately led to the same catalytic activity under large excess of $\mathrm{H}_{2}$ (PROX conditions) than that for the unpromoted state of the catalyst $(2 \mathrm{~V})$ in absence of $\mathrm{H}_{2}$. On the other hand it is interesting to note the similar trend between the open circuit potential and the catalytic activity and selectivity values during the composition transients. As already shown in previous studies [35] one can correlate the open circuit potential with the $\mathrm{O}_{2}$ coverage on a catalyst film supported on a solid electrolyte. Then the progressive decrease in the $\mathrm{O}_{2}$ coverage on the catalyst surface as the $\mathrm{H}_{2}$ composition in the feed increase, explained the observed decrease in the plotted parameters of conversion, selectivity and open circuit potential. Thus, it can be observed that during the first transient from $\mathrm{H}_{2} / \mathrm{O}_{2}=0$ to $\mathrm{H}_{2} /$ $\mathrm{O}_{2}=40$, a sharp decrease in the activity of the system enclosed a strong decrease in the $V^{\mathrm{o}}{ }_{\mathrm{wc}}$, indicating an important increase in the $\mathrm{H}_{2}$ coverage at the expense of $\mathrm{O}_{2}$. However, in the second transient from $\mathrm{H}_{2} / \mathrm{O}_{2}=40$ to $\mathrm{H}_{2} / \mathrm{O}_{2}=80$ a smaller decrease in the activity of the system enclosed a less pronounced decrease in the $V^{\mathrm{O}}{ }_{\text {wC }}$ (from -220 to $-225 \mathrm{mV}$ ). It suggests that this second increase in the $\mathrm{H}_{2} / \mathrm{O}_{2}$ ratio above 40 did not involve an important increase in the $\mathrm{H}_{2}$ coverage, since $\mathrm{H}_{2}$ was already in excess from the previous atmosphere. This assumption can be supported by the characterization of the system by cyclic voltammetry at the same temperature and under different reaction atmospheres.

Fig. 7 shows the current variation (zoomed at the anodic part) vs. the applied potential $\left(V_{\mathrm{wc}}\right)$ during the cyclic voltammetry between +2 and $-2 \mathrm{~V}$ carried out under He atmosphere and under reaction conditions with different $\mathrm{H}_{2}$ concentrations $\left(\mathrm{CO} / \mathrm{O}_{2}\right.$ : $0.4 \% / 0.2 \%$ ). As already demonstrated in previous studies $[29,36]$, the cathodic part of the cyclic voltammetry (negative potentials) could be linked to the migration of ions from the solid electrolyte to the catalyst-working electrode surface with the consequent formation of promoter derived compounds after interaction with the chemisorbed species [37]. On the other hand, the anodic part of the cyclic voltammetry could be linked to the decomposition of the previously formed species and the migration of the ions back to the solid electrolyte. Thus, taking into account that the gold counter electrode is in reference air and it is constituted by big particles of negligible activity [29-31], all electrochemical processes displayed on the anodic part of the voltammetry (Fig. 7) could be mainly attributed to the decomposition of surface compounds present on the Pt catalyst-working electrode. Without entering in a deep analysis of the different electrochemical processes, one can survey two main conclusions from the displayed voltammograms: 


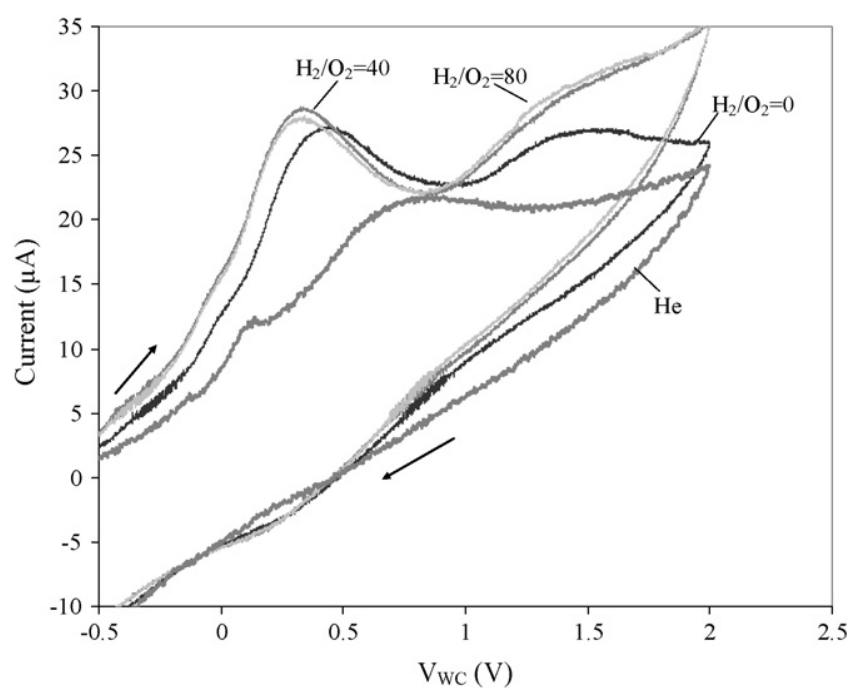

Fig. 7. Anodic zoom of the cyclic voltammograms at $195{ }^{\circ} \mathrm{C}$ between 2 and $-2 \mathrm{~V}$ under $\mathrm{He}$ atmosphere and under reaction conditions $\left(\mathrm{CO} / \mathrm{O}_{2}: 0.4 \% / 0.2 \%\right)$ with different $\mathrm{H}_{2} / \mathrm{O}_{2}$ ratios (0-80).

- Under presence of the reactant species $\left(\mathrm{CO}\right.$ and $\left.\mathrm{O}_{2}\right)$ the anodic part of the voltammetry clearly showed additional electrode processes (with higher charge transfer) in comparison with that obtained in absence of active chemisorbed species, i.e., He atmosphere. This is the result of the decomposition of promoting species previously formed between the promoter ions and the chemisorbed species.

- The increase in the $\mathrm{H}_{2}$ composition from $\mathrm{H}_{2} / \mathrm{O}_{2}=0$ to $\mathrm{H}_{2} / \mathrm{O}_{2}=40$ enhanced the intensity of the anodic charge transfer reaction, demonstrating that the observed anodic processes depended on the coverage of the different chemisorbed species. However, almost the same cyclic voltammogram was observed for $\mathrm{H}_{2} /$ $\mathrm{O}_{2}=40$ and $\mathrm{H}_{2} / \mathrm{O}_{2}=80$, indicating no modification in the competitive adsorption of reactants, regardless the concentration of species in the atmosphere surrounding the electrochemical catalyst.

Therefore, both in situ characterization techniques seem to indicate that a further increase in the $\mathrm{H}_{2}$ concentration above a certain value did not strongly modify the competitive adsorption among the reactants in the explored electrochemical catalyst. Consequently, the observed slight decrease in the activity of the system observed in Fig. 6 for $\mathrm{H}_{2} / \mathrm{O}_{2}>40$ could be mainly attributed to a non-catalytic $\mathrm{H}_{2}$ oxidation process.

\subsection{Stability of the NEMCA effect}

In order to investigate the stability of the electro-promotional effect, different transients were carried out keeping the system under open circuit conditions after previous polarizations. Fig. 8 shows the variation of the CO conversion vs. time under different potentiostatic transients and open circuit conditions carried out with a reactive mixture containing $\mathrm{CO} /$ $\mathrm{O}_{2} / \mathrm{H}_{2}: 0.4 \% / 0.2 \% / 16 \%$ at $175^{\circ} \mathrm{C}$. Consecutive negative polarizations at $-2 \mathrm{~V}$ during 15 min were carried out with intermediate open circuit steps (denoted as O.C.) during 30, 60 and $120 \mathrm{~min}$. Fig. $8 \mathrm{~b}$ additionally shows the variation of the current curves vs. time during the negative polarization of $-2 \mathrm{~V}$ along with the integral amount of charge supplied in each negative polarization step (consecutively denoted). Very interestingly, it can be observed that after the initial polarization of the system at $-2 \mathrm{~V}$, which consumed $-15.8 \mathrm{mC}$ of charge $\left(\theta_{\mathrm{K}}=0.024\right)$, the system kept its catalytic activity during the open circuit steps
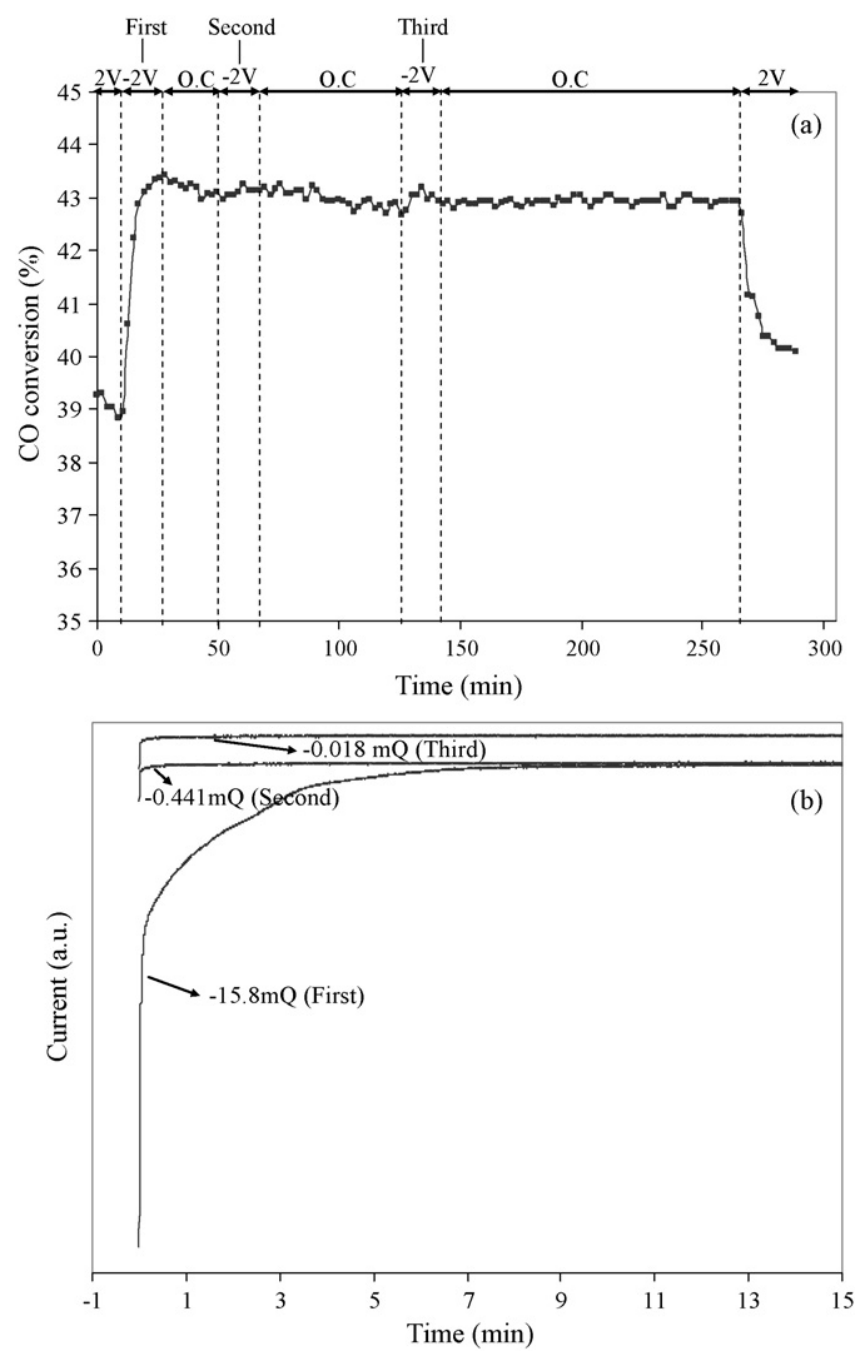

Fig. 8. (a) CO conversion vs. time under different applied potentials and open circuit potential steps (O.C.) at $175^{\circ} \mathrm{C}$. (b) Current vs. time curves and integral amount of transferred charge during the potentiostatic imposition of $-2 \mathrm{~V}$. Conditions: $\mathrm{CO} / \mathrm{O}_{2} /$ $\mathrm{H}_{2}: 0.4 \% / 0.2 \% / 16 \%$.

with almost no additional charge consumed in the subsequent polarizations. These results evidence the remarkable stability of the promotional phases under PROX reaction conditions, which could maintain a high catalytic activity for a long time. The low operation temperature of the system allows keeping a constant amount of promoter on the catalyst surface under open circuit conditions after an initial negative polarization leading to the observed permanent effect. This permanent phenomenon, already demonstrated in other NEMCA systems [29,38,39], is of great technological interest since it would decrease the electrical energy requirement of the cell. Thus, for the case of the PROX unit, one can envisage an electrochemical catalyst with only a primary polarization step, which leads to the initial activation of the system. Then, very short polarization steps will be required to adjust the optimum potential conditions and therefore the optimum promoter coverage, depending on the operating environment (composition and temperature) of the outlet reforming unit stream.

\section{Conclusions}

Different findings of theoretical and technological importance can be emphasized from this work as a result of coupling catalysis and solid state electrochemistry for the PROX reaction: 
- The activity and selectivity for the PROX process can be strongly enhanced by the phenomenon of electrochemical promotion. This phenomenon would allow optimizing the amount of promoter under the expected dynamic conditions of a PROX unit which is not possible with a conventional promoted heterogeneous catalyst.

- NEMCA effect allows activating the Pt catalyst at lower temperatures for the preferential $\mathrm{CO}$ oxidation reaction. Additionally, it allows decreasing the inhibiting effect of the temperature on the $\mathrm{CO}_{2}$ selectivity.

- The phenomenon of electrochemical promotion also allows attenuating the inhibiting effect of $\mathrm{H}_{2}$ over the activity and selectivity under different explored compositions $\left(\mathrm{H}_{2} / \mathrm{O}_{2}\right.$ ratio).

- The observed permanent NEMCA effect demonstrates the high stability of the promoting species under PROX working conditions. In addition, it shows a great potential for the further development of these systems in real configuration minimizing the electrical energy requirements.

\section{Acknowledgments}

Financial support by the Ministerio de Educación y Ciencia of Spain (projects: CTQ 2007-62512/PPQ) and the European MarieCurie EFEPOC project (MSCF-CT-2006-046201) are gratefully acknowledged. Financial and technical support by Saint-Gobain CREE is also gratefully acknowledged. A. de Lucas-Consuegra also thanks to the University of Castilla-La Mancha for a post-doc scholarship in Saint-Gobain CREE. The authors also thank to the reviewers for its remarks and suggestions to improve the paper.

\section{References}

[1] C. Song, Catal. Today 77 (2002) 17-49.

[2] E.D. Park, D. Lee, H.C. Lee, Catal. Today 139 (2009) 280-290.

[3] H. Tanaka, S. Ito, S. Kameoka, K. Tomishige, K. Kunimori, Appl. Catal. A: Gen. 250 (2003) 255-263.

[4] F. Marino, C. Descorme, D. Duprez, Appl. Catal. B: Environ. 54 (2004) 59-66.

[5] G. Avgouropoulos, T. Ioannides, Ch. Papadopoulou, J. Batista, S. Hocevar, H.K. Matralis, Catal. Today 75 (2002) 157-167.

[6] S. Zhou, Z. Yuan, S. Wang, Int. J. Hydrogen Energy 31 (2006) 924-933.

[7] Y. Kim, E. Park, H. Lee, D. Lee, K. Lee, Catal. Today 146 (2009) 253-259.
[8] M. Kotobuki, A. Watanabe, H. Uchida, H. Yamashita, M. Watanabe, Chem. Lett. 34 (2005) 866-867.

[9] I.H. Son, M. Shamsuzzoha, A.M. Lane, J. Catal. 210 (2002) 460-465.

[10] S.Y. Chin, O.S. Alexeev, M.D. Amiridis, J. Catal. 243 (2006) 329-339.

[11] H. Tanaka, S. Ito, S. Kameoka, K. Tomishige, K. Kunimori, Catal. Commun. 4 (2003) $1-4$.

[12] S. Ito, H. Tanaka, Y. Minemura, S. Kameoka, K. Tomishige, K. Kunimori, Appl. Catal. A: Gen. 273 (2004) 295-302.

[13] Y. Minemura, S.I. Ito, T. Miyao, S. Naito, K. Tomishige, K. Kunimori, Chem. Commun. 11 (2005) 1429-1431.

[14] Y. Minemura, M. Kuriyama, S.I. Ito, K. Tomishige, K. Kunimori, Catal. Commun. 7 (2006) 623-626.

[15] M. Kuriyama, H. Tanaka, S.I. Ito, T. Kubota, T. Miyao, S. Naito, K. Tomishige, K. Kunimori, J. Catal. 252 (2007) 39-48.

[16] H. Tanaka, M. Kuriyama, Y. Ishida, S.I. Ito, K. Tomishige, K. Kunimori, Appl. Catal. A 343 (2008) 117-124.

[17] C.G. Vayenas, M.M. Jaksic, S. Bebelis, S.G. Neophitides, in: J.O.M. Bokris, B.E. Conway, R.E. White (Eds.), Modern Aspects of Electrochemistry, vol. 29, Plenum, New York, 1996, p. 57.

[18] C.G. Vayenas, S. Bebelis, C. Pliangos, S. Brosda, D. Tsiplakides, Electrochemical Activation of Catalysis: Promotion, Electrochemical Promotion and Metal-Support Interactions, Kluwer Academic Publishers/Plenum Press, New York, 2001.

[19] C.G. Vayenas, S. Bebelis, S. Ladas, Nature (London) 343 (1990) 625-627.

[20] C.G. Vayenas, S. Bebelis, I.V. Yentekakis, H.-G. Lintz, Catal. Today 11 (1992) 303438.

[21] A. Katsaounis, J. Appl. Electrochem. (in press) doi:10.1007/s10800-009r-r9938-7.

[22] D. Tsiplakides, S. Balomenou, Chem. Ind. Chem. Eng. Quart. 14 (2008) 97-105

[23] F. Sapontzi, N.N. Tsampas, C.G. Vayenas, Top. Catal. 44 (2007) 461-468.

[24] F. Sapontzi, N.N. Tsampas, C.G. Vayenas, Catal. Today 127 (2007) 295-303.

[25] F. Sapontzi, N.N. Tsampas, C.G. Vayenas, Catal. Today 146 (2009) 319-325.

[26] X. Li, F. Gaillard, P. Vernoux, Top. Catal. 44 (2007) 391-398.

[27] S. Brosda, C.G. Vayenas, J. Wei, Appl. Catal. B: Environ. 68 (2006) 109-124.

[28] G. Goula, P. Katzourakis, N. Vakakis, T. Papadam, M. Konsolakis, M. Tikhov, I.V. Yentekakis, Catal. Today 127 (2007) 199-206.

[29] A. de Lucas-Consuegra, F. Dorado, J.L. Valverde, R. Karoum, P. Vernoux, J. Catal. 251 (2007) 474-484.

[30] A. de Lucas-Consuegra, F. Dorado, J.L. Valverde, R. Karoum, P. Vernoux, Catal. Commun. 9 (2008) 17-20.

[31] A. de Lucas-Consuegra, A. Caravaca, F. Dorado, J.L. Valverde, Catal. Today 146 (2009) 330-335.

[32] J.L. Ayastuy, M.P. Gonzalez-Marcos, J.R. Gonzalez-Velasco, M.A. Gutierrez-Ortiz, Appl. Catal. B 70 (2007) 532-541.

[33] I.N. Yakovkin, V.I. Chernyi, A.G. Naumovets, Surf. Sci. 442 (1999) 81-89.

[34] J. Bergeld, B. Kasemo, D.K. Chakarov, Surf. Sci. 495 (2001) L815-820.

[35] X. Li, F. Gaillard, P. Vernoux, Ionics 11 (2005) 103-111.

[36] F. Dorado, A. de Lucas-Consuegra, P. Vernoux, J.L. Valverde, Appl. Catal. B 73 (2007) 42-50.

[37] P. Vernoux, F. Gaillard, C. Lopez, E. Siebert, Solid State Ionics 175 (2004) 609-613.

[38] E. Varkaraki, J. Nicole, E. Plattner, C. Comninellis, J. Appl. Electrochem. 25 (1995) 978-981.

[39] D. Tsiplakides, J. Nicole, C.G. Vayenas, C. Comninellis, J. Electrochem. Soc. 145 (1998) 905-908. 